Research Article

\title{
Empirical Analysis on Promoting Industrial Transformation and Upgrading in Zhejiang Province by Enhancing Intellectual Property Protection
}

\author{
Junjun Ye $\mathbb{1}^{1},{ }^{1}$ Jijian Wang, ${ }^{2}$ and Zhiwei Zhu ${ }^{1}$ \\ ${ }^{1}$ School of Intellectual Property, Zhejiang Industry \& Trade Vocational College, Wenzhou 325003, China \\ ${ }^{2}$ School of Humanities, Zhejiang Industry \& Trade Vocational College, Wenzhou 325003, China \\ Correspondence should be addressed to Junjun Ye; yejunjun@zjitc.edu.cn
}

Received 3 November 2021; Revised 2 December 2021; Accepted 4 December 2021; Published 20 December 2021

Academic Editor: Ahmed Farouk

Copyright (c) 2021 Junjun Ye et al. This is an open access article distributed under the Creative Commons Attribution License, which permits unrestricted use, distribution, and reproduction in any medium, provided the original work is properly cited.

This paper aims to reveal the relationship between intellectual property protection (IPP) and industrial transformation and upgrading $(\mathrm{T} \& \mathrm{U})$ in southeastern China's Zhejiang Province. Taking five representative industries as objects, the shift-share analysis was adopted to measure the T\&U level of each industry, with the total output in 2004-2019 as the basis. The results show that wholesale and retail, lodging and catering, finance, and real estate are the four advantageous industries. Further, the authors calculated Pearson's correlation coefficients between IPP intensity and the T\&U levels of the four industries. By the coefficients, the four industries can be ranked in descending order as lodging and catering (0.8743), real estate (0.6908), wholesale and retail (0.5891), and finance (0.5468). In addition, the IPP was found to be positively correlated with total manufacturing output (0.8027). Hence, the IPP can significantly promote the development of these five industries.

\section{Introduction}

China is currently in the midway of industrialization. The transformation and upgrading (T\&U) of traditional industries become an important task in the new era. The numerous traditional industries cover a wide range of areas in China and contribute more than $50 \%$ of the country's industrial output, job opportunities, and fiscal revenue [1]. They are the pillars of China's social and economic development. However, most traditional industries face pressure from both overcapacity, and energy saving and emission reduction. There is an urgent need to transform and upgrade traditional industries and to adjust and optimize the industrial structure.

\section{Literature Review}

On the T\&U of traditional industries, the most influential theories include the theory of industrial lifecycle [2], the theory of commercial ecosystem $[3,4]$, and the theory of industrial organization and competition. Currently, the domestic literature of the $T \& U$ of traditional industries focusses on the following four aspects.

The first aspect is the T\&U ways or paths of traditional industries. The relevant scholars have comprehensively considered factors such as market demand and technical level, cultivated advanced production factors, trained competitive production and management subjects, and improved the demand quality, enhanced technical capabilities for research and development (R\&D) and technical diffusion, leveraged organization-to-organization (O2O) platforms, used mathematical models to select the paths of elimination, maintenance, and transformation, synthetized multiple paths, such as compulsory policies, technical promotion, industrial cluster development, performance appraisal, and regional economic cooperation, and pursued value creation, brand building, servitization, platformization, and greenization [5-10].

The second aspect is the T\&U mechanisms of traditional industries: market demand pulling mechanism, competitive 
pressure mechanism, technological innovation driving mechanism, overall operating mechanism of government support, and the parallel mechanism of decapacity through market selection, and the development of strategic emerging industries supported by industrial innovation $[11,12]$.

The third aspect is the T\&U performance appraisal of traditional industries. The relevant scholars have constructed a comprehensive evaluation index system (EIS) of five aspects: regional economic development, technological innovation, level of industrial structure, degree of economic opening, and eco-environmental governance, and revealed the operating mechanism of industrial upgrading in underdeveloped areas through technical innovation $[13,14]$.

The fourth aspect is the T\&U measuring methods of traditional industries, including but not limited to the measurement of industrial updating progress and direction, and the shift-share analysis [15].

The development of strategic emerging industries is underpinned by independent intellectual property rights (IPR). The enhancement of intellectual property protection (IPP) becomes a major strategy for building an innovative country. However, there is no report on how IPP promotes the T\&U of traditional industries. The related studies can be allocated to three categories: first, the influence of IPP on international trade, economic growth, industrial growth, and technological innovation [16-18]; second, the strengthening of IPP research in specific areas, such as creative industries, agriculture, Chinese medicine industry, digital information resources, etc. [19-22]; and third, the IPP research from specific perspectives like culture and balance of interests $[23,24]$.

Currently, the level of industrial T\&U is mainly measured from three angles: speed, direction, and height $[25,26]$. The speed of industrial T\&U is mostly evaluated by Lilien index, More value, and annual mean variation of industrial structure. The direction of industrial T\&U is primarily assessed with the advancement index of industrial structure. The height of industrial T\&U is generally measured by the sum of various industrial structure ratios. With industrial structure (or employment structure) as the basis, the speed, direction, and height indices all depict the variation of industrial structure to reflect the industrial T\&U level. These indices at most mirror the structural advantage of an industry or the T\&U level of the entire economic system, failing to demonstrate the location competitiveness of an industry.

To sum up, there has been extensive research into the paths, mechanisms, and performance of the T\&U of traditional industries and the promoting effect of IPP on specific industries. Nevertheless, the following issues have not been well explored: (1) the relationship between IPP intensity and the T\&U level of traditional industries; (2) the region-based research into the promoting effect of IPP on the T\&U of traditional industries; and (3) the empirical analysis based on econometric approaches.

This paper surveys the total outputs of five representative industries in Zhejiang from 2004 to 2019 and examines the relationship between IPP and the T\&U of the five industries, providing supports to the decision-making of relevant government departments.

\section{T\&U Level Index of Traditional Industries}

This paper measures the T\&U level of each industry through shift-share analysis. Taking the relevant data of Zhejiang in 2004-2019 for example, the dynamic T\&U level index was obtained for each industry in the province in each year.

3.1. Measurement of T\&U Level. Shift-share analysis was proposed by American economists Daniel and Creamer and summarized and improved by Dunn et al. It is widely adopted at home and abroad to analyze the benefits of regional economy and industrial structure [27-29]. Through shift-share analysis, the economic development of the study area in the planning horizon is compared with that of the standard area (i.e., the benchmark) to measure the precise competitiveness of each sector or industry in the study area relative to that in the standard area. This analysis approach is known for its comprehensiveness and dynamicity. Wang [30] relied on shiftshare analysis to measure the industrial T\&U in Hebei Province, China.

Taking five industries in Zhejiang for example, the five industries in China were chosen as the reference objects, and the report period was set to 1 year.

Let $y^{0}$ and $y^{t}$ be the total output of the five industries in Zhejiang in the base period and the report period, respectively; $y_{j}^{0}$ and $y_{j}^{t}$ be the total output of industry $j$ in Zhejiang in the base period and the report period, respectively; $Y^{0}$ and $Y^{t}$ be the total output of the five industries in China in the base period and the report period, respectively; $Y_{j}^{0}$ and $Y_{j}^{t}$ be the total output of industry $j$ in China in the base period and the report period, respectively, with $j=1,2, \ldots, 5$ being the serial numbers of the five industries.

From the base period to the report period, the change rate of industry $j$ in Zhejiang, the change rate of industry $j$ in China, the change rate of the total output of the five industries in China, and the increment of industry $j$ in Zhejiang can be respectively expressed as

$$
\begin{aligned}
r_{j}= & \frac{y_{j}^{t}-y_{j}^{0}}{y_{j}^{0}}, \quad j=1,2, \ldots, 5, \\
R_{j}= & \frac{Y_{j}^{t}-Y_{j}^{0}}{Y_{j}^{0}}, \quad j=1,2, \ldots, 5, \\
R= & \frac{Y^{t}-Y^{0}}{Y^{0}}, \\
G_{j}= & Y_{j}^{t}-Y_{j}^{0}=Y_{j}^{0} r_{j}=y_{j}^{0} R+\left(y_{j}^{0} R_{j}-y_{j}^{0} R\right) \\
& +\left(y_{j}^{0} r_{j}-y_{j}^{0} R_{j}\right), \quad j=1,2, \ldots, 5,
\end{aligned}
$$




$$
\begin{aligned}
N_{j} & =y_{j}^{0} R, \\
P_{j} & =y_{j}^{0} R_{j}-y_{j}^{0} R, \\
D_{j} & =y_{j}^{0} r_{j}-y_{j}^{0} R_{j}, \\
S_{j} & =P_{j}+D_{j} .
\end{aligned}
$$

Then,

$$
G_{j}=N_{j}+P_{j}+D_{j}=N_{j}+S_{j}, \quad j=1,2, \ldots, 5,
$$

where $N_{j}$ is the share of industry $j$ in China, i.e., the output increment of industry $j$ in Zhejiang growing at the growth rate of the tertiary industry (the mean growth rate of all industries) in China; $P_{j}$ is the structural shift of industry $j$, i.e., the increment of industry $j$ brought by the comparative advantage of industrial structure (if $P_{j}>0$, industry $j$ in Zhejiang has an advantageous industrial structure; otherwise, industry $j$ in Zhejiang does not have an advantageous industrial structure); $D_{j}$ is the competitiveness shift of industry $j$, i.e., the increment of industry $j$ brought by location competitiveness (if $D_{j}>0$, industry $j$ in Zhejiang has an location competitiveness; otherwise, industry $j$ in Zhejiang does not have an location competitiveness); $S_{j}$ is the total shift of industry $j$ (if $N_{j}>0$ and $S_{j}>0$, industry $j$ is an advantageous industry; if $P_{j}>0$ and $D_{j}>0$, industry $j$ has a good structure and a strong competitiveness) [22].

3.2. Data Collection. Following the principles of data representativeness and availability, five industries were selected for this study according to the industrial classification in China Statistical Yearbook (2019): manufacturing (industry 1 ), wholesale and retail (industry 2), lodging and catering (industry 3), finance (industry 4), and real estate (industry 5). All these industries are physical industries, except finance, a nonphysical industry.

The total outputs of the five industries in 2004-2019 were collected from Zhejiang Statistical Yearbooks and China Statistical Yearbooks.

3.3. TeU Level Index of Each Industry in Zhejiang. The share component, structure component, and location competitiveness component of the five industries in Zhejiang were calculated by shift-share analysis. The calculation process of shiftshare analysis was explained with manufacturing in 2004-2005 for example. From the base period to the report period, the change rate of manufacturing in Zhejiang can be calculated by

$$
r_{1}=\frac{(6345-5491)}{5491}=0.1554 \text {. }
$$

The change rate of manufacturing in China can be calculated by

$$
R_{1}=\frac{(77961-65777)}{65777}=0.1852 .
$$

From the base period to the report period, the change rate of the total output of the five industries in China was $R=0.1715$. Thus, the share component, structure component, and location competitiveness component in Zhejiang can be calculated by

$$
\begin{aligned}
N_{1} & =5491 \times 0.1715 \approx 941, \\
P_{1} & =5491 \times(0.1852-0.1715) \approx 75, \\
D_{1} & =5491 \times(0.1554-0.1852) \approx-164 .
\end{aligned}
$$

Table 1 lists all the results of the shift-share analysis.

\subsection{Results Analysis and Discussion}

3.4.1. Analysis on Industrial Advantages. Based on Table 1, the $T \& U$ trends of the five industries were plotted (Figures 1-5). The following conclusions can be drawn from the corresponding figures: in Zhejiang, manufacturing lacks structural advantage and location advantage, as both advantages were falling in the report period; wholesale and retail has structural advantage, which slowly increased in the report period, but lacks location advantage, which slowly declined; lodging and catering lacks structural advantage, which slowly decreased in the report period, but has location advantage, which rose quickly; the finance has structural advantage, which increased at a fast pace, and a fluctuating location advantage, which was weak before 2011 and declined to zero afterwards; the real estate has structural advantage, which quickly increased, but lacks location advantage, which quickly declined.

3.4.2. Horizontal Comparison of Industrial Advantages. Based on Table 1, the trends of the share, structure advantage, and location advantage were drawn for the five industries (Figures 6-8). The relevant figures reveal that the share of manufacturing (industry 1) increased much faster than that of any other industry; manufacturing (industry 1) lacks structural advantage, trailing far behind the other industries, while finance (industry 4) has structural advantage, which is far above that of any other industry; lodging and catering (industry 3 ) is the only industry among the five that has location advantage, while all the other industries, particularly manufacturing, lack that advantage.

3.4.3. Analysis on Advantageous Industries. Based on Table 1, the total shift $S_{j}$ was calculated and judged if it is greater than 0 . Then, the trends of the total shift of the five industries were plotted (Figure 9). The following conclusions can be drawn from that figure:

(1) Manufacturing is not an advantageous industry in Zhejiang

(2) Wholesale and retail became an advantageous industry in Zhejiang since 2012

(3) Lodging and catering became an advantageous industry in Zhejiang since 2014

(4) Finance had always been an advantageous industry in Zhejiang

(5) Real estate oscillated about the level of being an advantageous industry, and it was an advantageous industry in 2017-2019, and not an advantageous industry in the other years. 


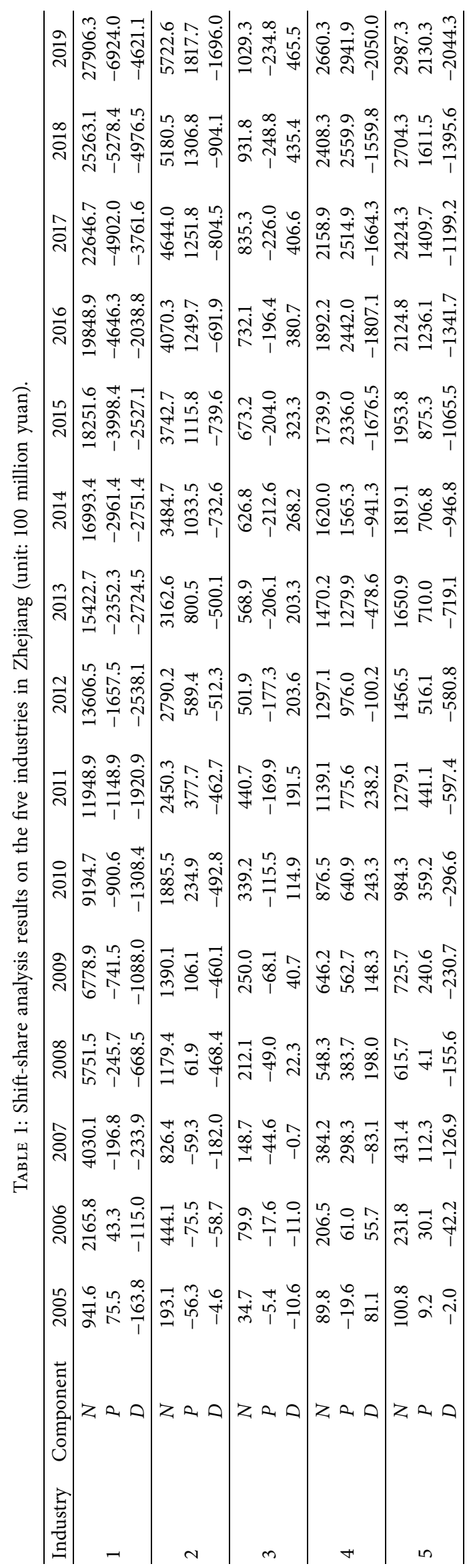




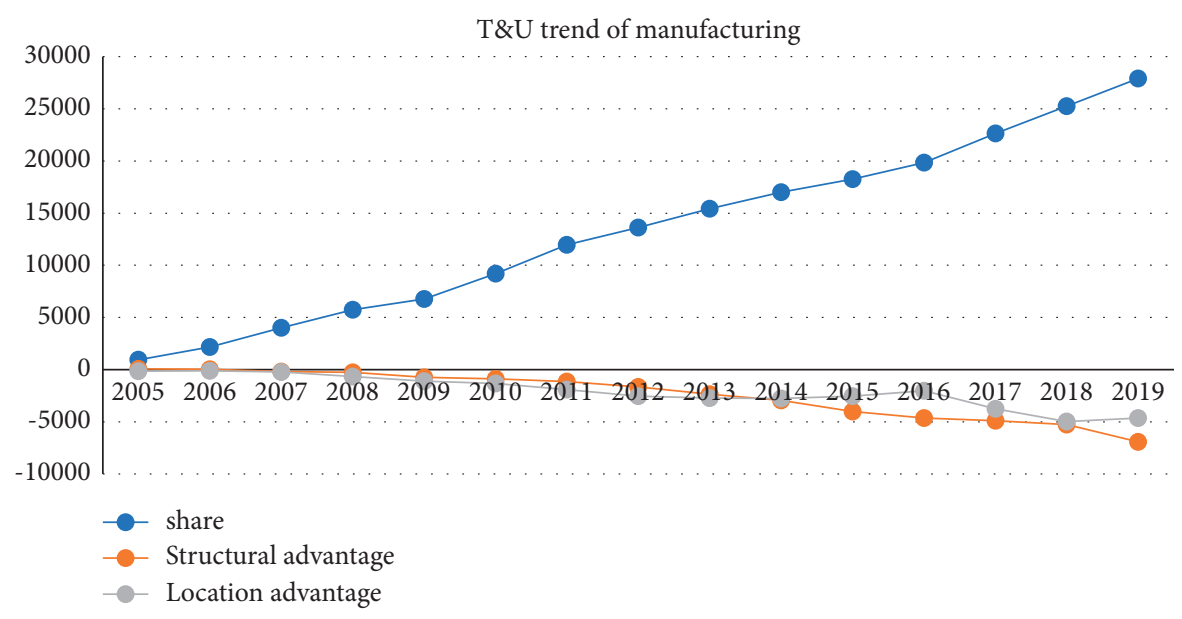

Figure 1: T\&U trend of manufacturing.

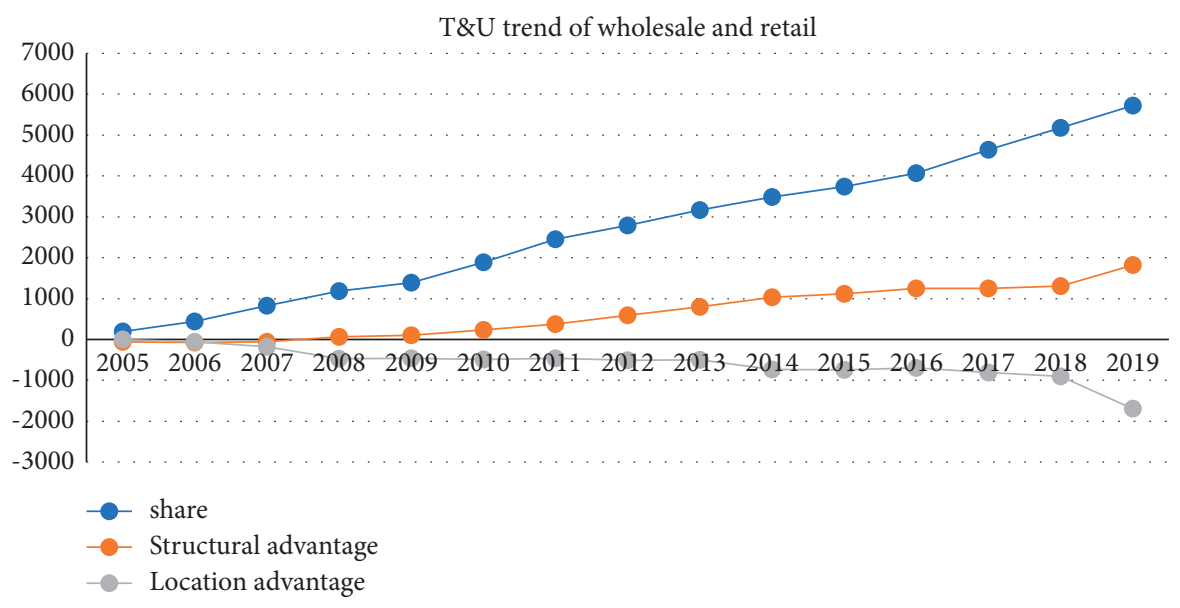

Figure 2: T\&U trend of wholesale and retail.

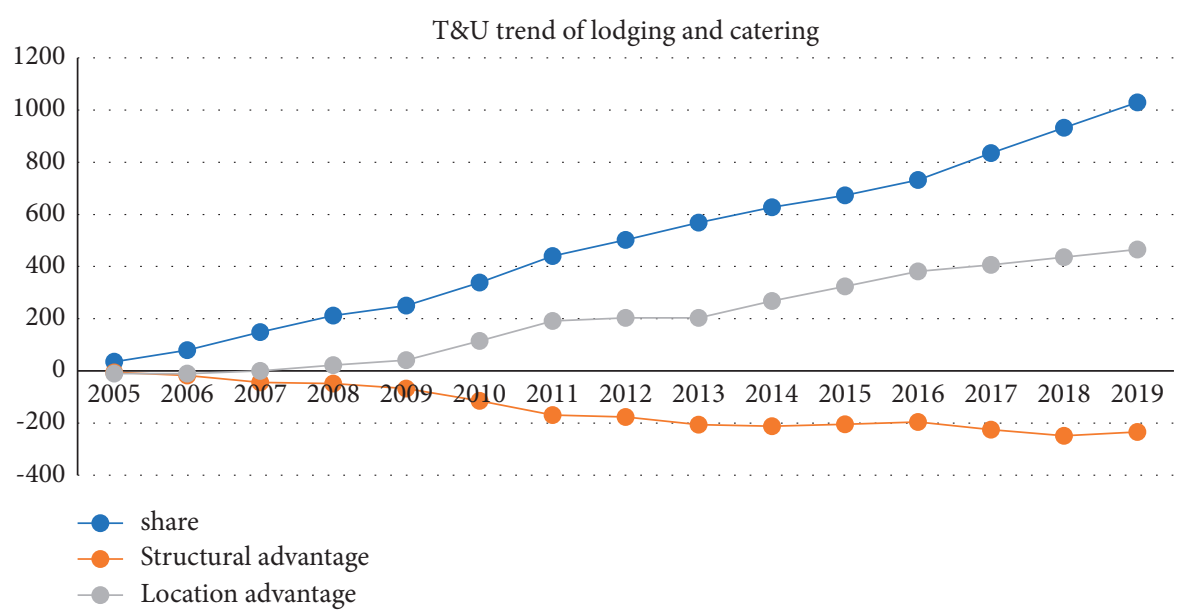

FIGURE 3: T\&U trend of lodging and catering.

3.4.4. Results Analysis and Discussion. According to the above data on the share, structural advantage, and location advantage of the five industries in recent five years, in the long run, finance, wholesale and retail, lodging and catering, and real estate are the advantageous industries of Zhejiang, because they not only boast a large development potential, but also have structural and location advantages. Zhejiang should vigorously support and invest in these key industries. Despite 


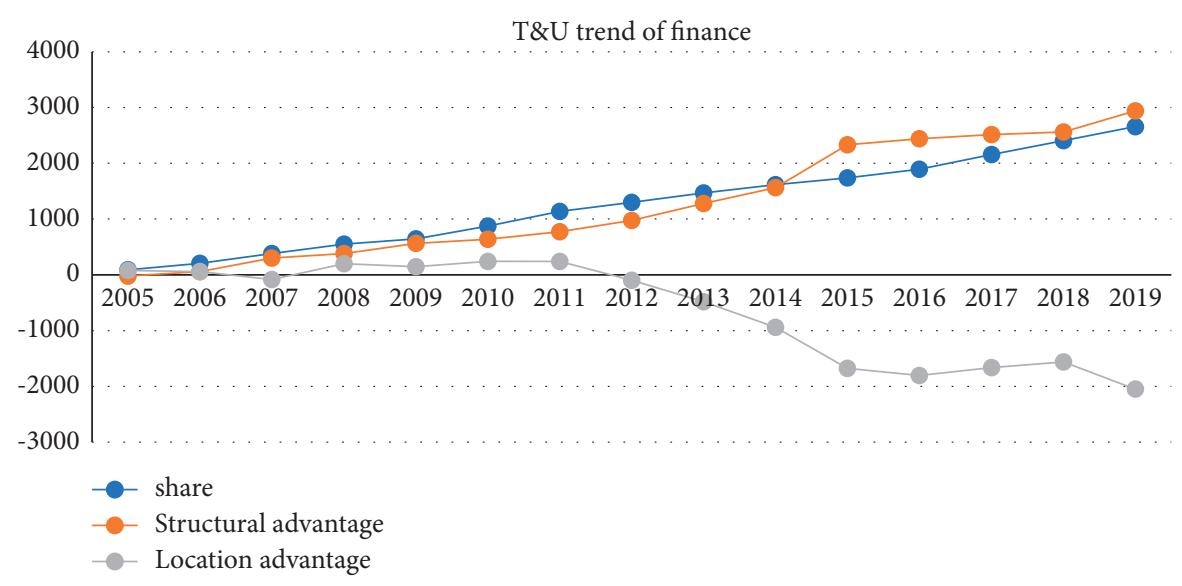

FIGURE 4: T\&U trend of finance.

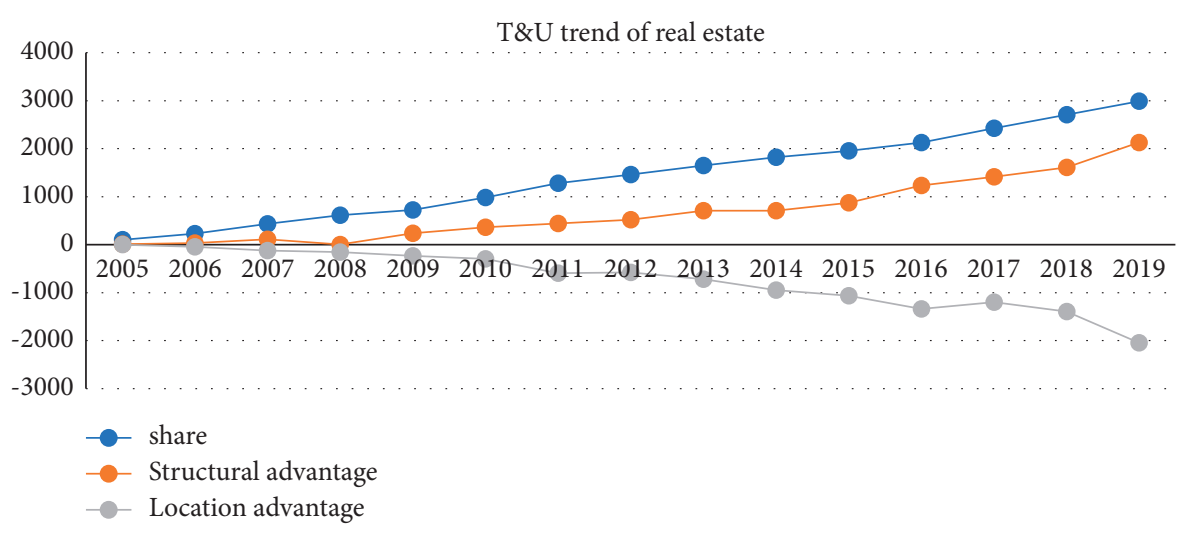

Figure 5: T\&U trend of real estate.

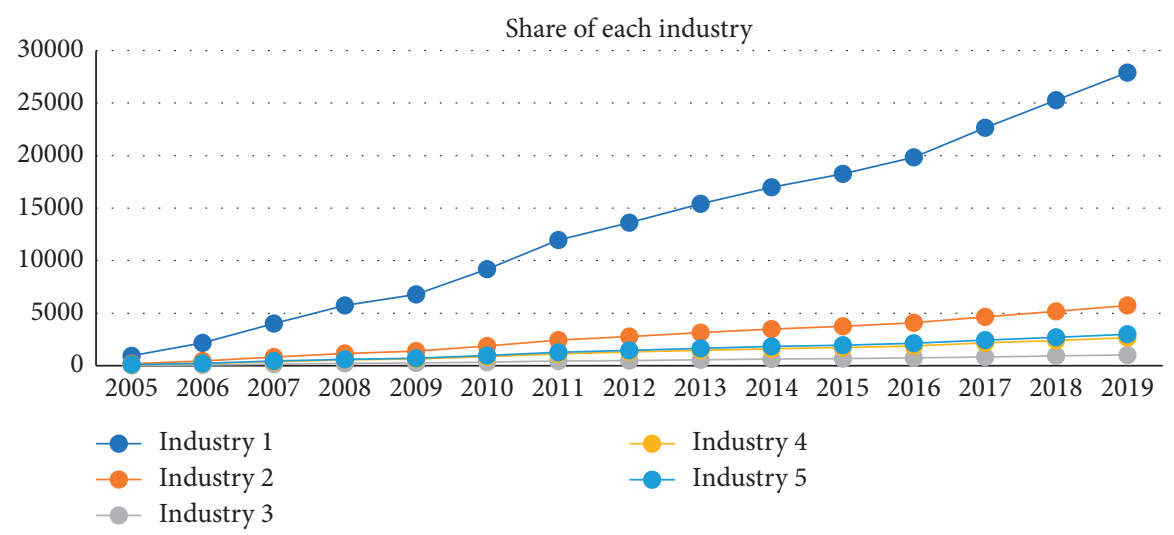

FIGURE 6: Share of each industry.

its fast-growing share, manufacturing lacks structural and location advantages. Zhejiang should continue to promote the $\mathrm{T} \& \mathrm{U}$ of manufacturing.

In Zhejiang, the five industries differ in structural and location advantages. Judging by share, all of them are growing industries. To a certain extent, the results show that Zhejiang has maintained a fast development of industries and achieved some effects of industrial T\&U. But not all its industries have passed the inflection point of industrial
T\&U. Zhejiang is now accelerating technology innovation and trying to promote high-quality development. Against this backdrop, innovation has always been viewed as the key path for each industry in the province to realize T\&U. In recent years, the IPP has become the pillar of innovationdriven industrial T\&U and socioeconomic development in Zhejiang. Hence, the relationship between IPP and the T\&U of traditional industries will be discussed in the following section. 


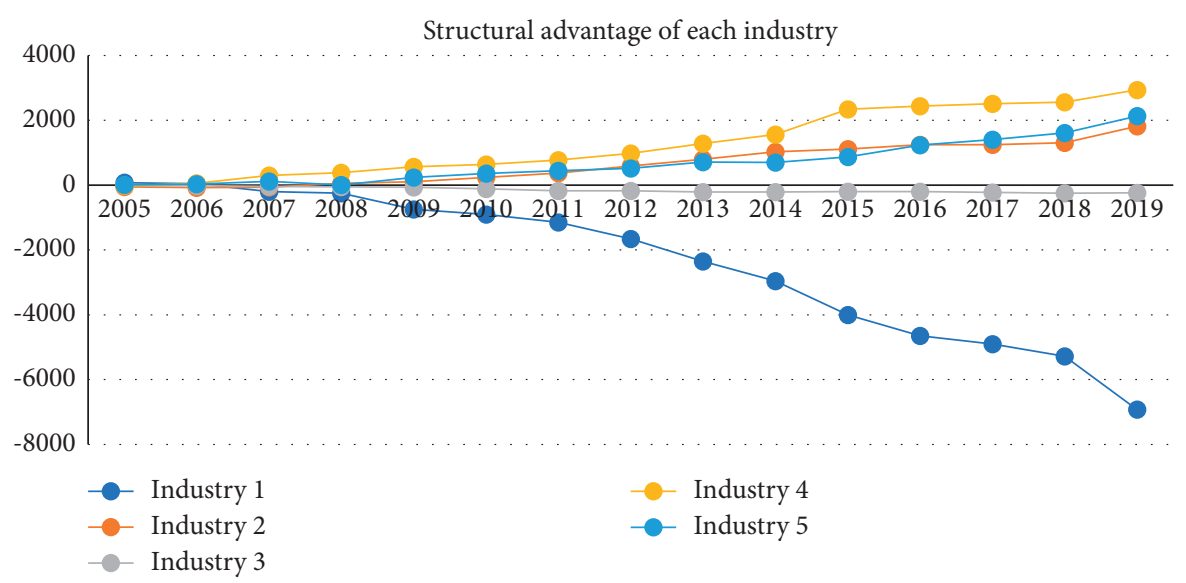

Figure 7: Structural advantage of each industry.

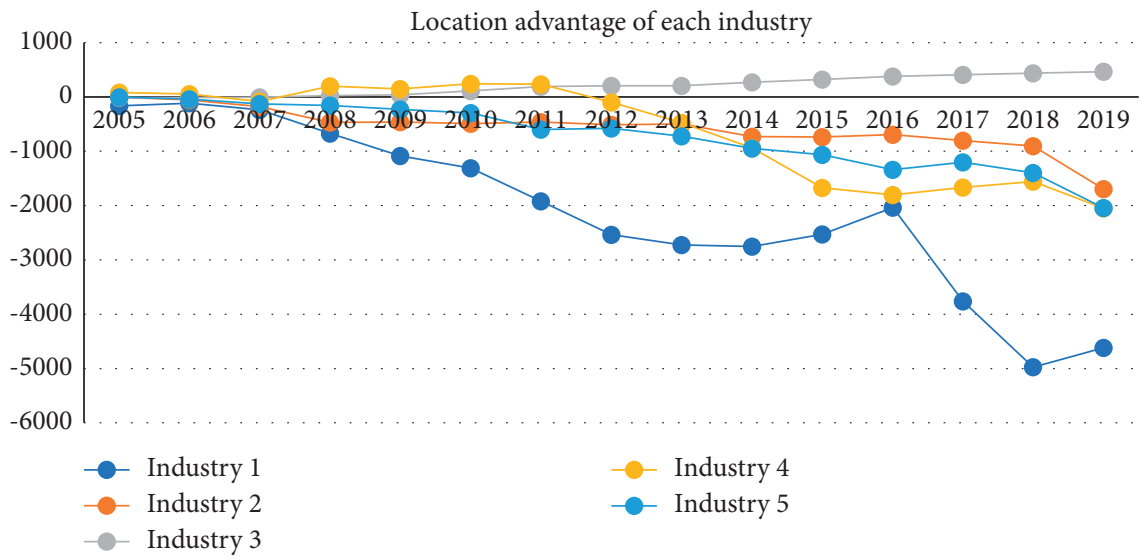

FIgURE 8: Location advantage of each industry.

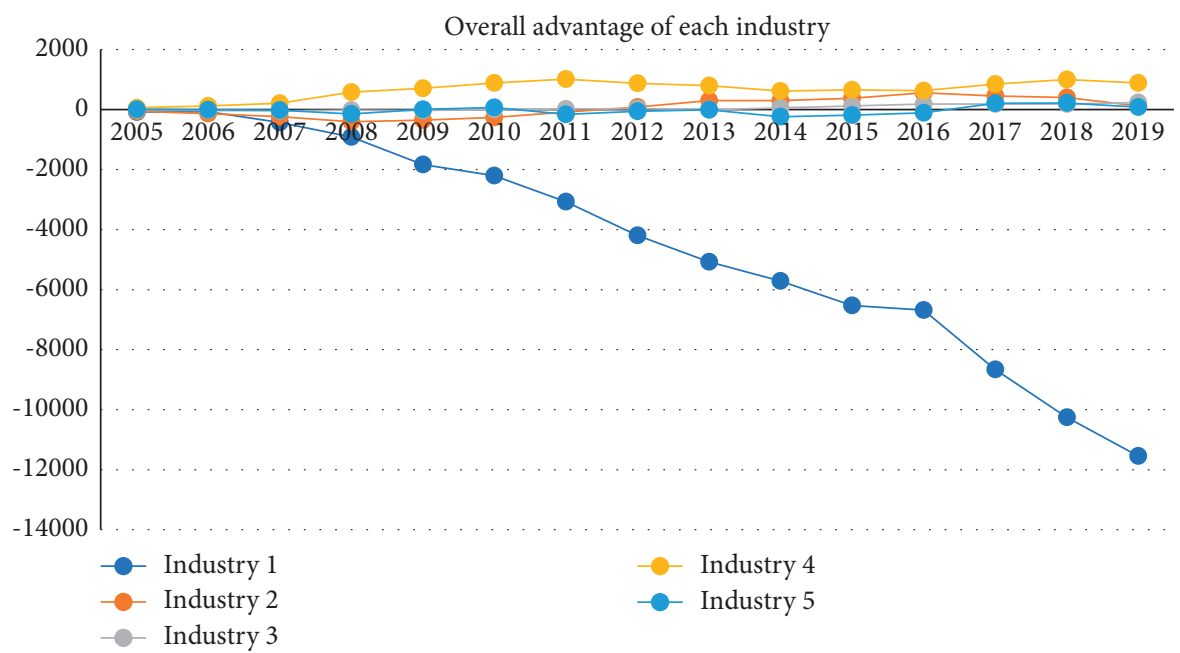

FIGURE 9: Overall advantage of each industry. 


\section{Relationship between IPP and T\&U of Traditional Industries}

Advantageous industries are those leading industrial T\&U. Many factors could promote the T\&U of industries. From the angle of IPP, this section discusses the promoting effect of IPP on industrial T\&U by computing the correlation coefficients between IPP intensity and the T\&U level of traditional industries.

4.1. Correlation Analysis [31]. Correlation analysis is a statistical method to study the direction and degree of linear correlation between two or more variables. The most common tool of correlation analysis is simple correlation coefficient, i.e., Pearson's correlation coefficient.

Let $\left(x_{i}, y_{i}\right)$ be $n$ sets of observations, $i=1,2, \ldots, n$. Then, the correlation coefficient between variables $x$ and $y$ can be expressed as

$$
r=\frac{\sum_{i=1}^{n}\left(x_{i}-\bar{x}\right)\left(y_{i}-\bar{y}\right)}{\sqrt{\sum_{i=1}^{n}\left(x_{i}-\bar{x}\right)^{2} \sum_{i=1}^{n}\left(y_{i}-\bar{y}\right)^{2}}},
$$

where $\bar{x}=1 / n \sum_{i=1}^{n} x_{i}, \bar{y}=1 / n \sum_{i=1}^{n} y_{i}$.

The correlation coefficient falls in the range of $-1 \leq r \leq 1$. If $r>0, x$ is positively correlated with $y$; if $r<0, x$ is negatively correlated with $y$. The closer the correlation coefficient $|r|$ is to 1 , the stronger the correlation between $x$ and $y$; the closer the correlation coefficient $|r|$ is to 0 , the weaker the correlation between $x$ and $y$. The significance of the correlation coefficient is verified through the $t$-test. The null hypothesis $H_{0}: r=0$ holds that the two variables do not have a significant linear relationship. The t-statistic can be expressed as

$$
t=r \sqrt{\frac{n-2}{1-r^{2}}}
$$

For a given significance level $\alpha$, if $|t|>t_{\alpha / 2}$, then the null hypothesis is rejected, and $r$ is considered as significant; otherwise, the null hypothesis is accepted, and $r$ is considered as insignificant. Or, if the $p$ value is smaller than $\alpha$, the hull hypothesis $H_{0}$ is rejected; otherwise, $H_{0}$ is accepted.

4.2. Results of Correlation Analysis. According to the results of our previous research [32, 33], the IPP intensities of Zhejiang in 2004-2019 were obtained as shown in Table 2.

Take real estate (industry 5) for example. Let $x$ and $y$ be the IPP intensity and the T\&U level of real estate (industry 5 ), respectively. Then, the T\&U level is the sum of structural shift component and competitiveness shift component: $y=P_{5}+D_{5}$. By formula (10), it can be calculated that the correlation coefficient between IPP intensity and T\&U level was 0.6908 , and the corresponding $p$ value was 0.0044 . If the given significance level was 0.05 , then $0.0044<0.05$, indicating that IPP intensity is significantly positively correlated with the T\&U level of real estate.

The correlations between the other four industries, manufacturing (industry 1), wholesale and retail (industry
2), lodging and catering (industry 3), finance (industry 4), the IPP intensity were tested similarly.

For manufacturing (industry 1), the correlation coefficient $(-0.8939)$ is inconsistent with the relevant theories and the actual situation. Hence, the correlation between IPP intensity and manufacturing output was evaluated directly: $y=N_{1}+D_{1}+P_{1}$. By formula (10), it can be calculated that the correlation coefficient between IPP intensity and T\&U level was 0.8027 , and the corresponding $p$ value was 0.0001 . If the given significance level was 0.05 , then $0.0001<0.05$, indicating that IPP intensity is significantly positively correlated with the T\&U level of manufacturing.

Table 3 presents the correlation coefficients and significance test results of all five industries.

As shown in Table 3, concerning manufacturing (industry 1), wholesale and retail (industry 2), lodging and catering (industry 3), finance (industry 4), and real estate (industry 5), the IPP has a significant positive correlation with industrial T\&U.

4.3. Results Analysis and Discussion. According to Pearson's correlations, the five industries can be ranked in descending order of the positive correlation intensity between their T\&U and IPP as lodging and catering (0.8743), real estate (0.6908), wholesale and retail (0.5891), and finance (0.5468). Among them, lodging and catering, real estate, and wholesale and retail are physical economy, while finance is virtual economy. Therefore, the IPP can simultaneously promote the development of some physical and virtual economies.

The correlation coefficients indicate that, among the five industries, the IPP exerts the most significant positive influence over the T\&U of lodging and catering (passing the significance test at the level of 0.01). The competitiveness of this tertiary industry can be greatly enhanced by such intellectual property operations as patent operation, trademark operation, and antiunfair competition. Specifically, trademark operation strengthens the brand effect of the industry by reducing the counterfeit risk and legally protecting market development models like brand development, franchising, trademark licensing, and chain development. Patent operation guarantees the innovations of lodging and catering, namely, applying for patent protection of production equipment and product appearance. Antiunfair competition prevents the plagiarism of commercial secrets, commodity packaging, advertising, and decoration design in the industry.

The IPP also significantly promotes the T\&U of real estate (passing the significance test at the level of 0.01 ), which integrates integrating various economic activities. The industry involves a variety of operations, such as building development, construction, operation, management, maintenance, decoration, and service. Many of these operations require the protection of copyrights, trademarks, and patents, as well as antiunfair competition, such as building design, interior design, building construction, corporate brand operation, advertising, and business information confidentiality. 
TABLE 2: IPP intensities of Zhejiang.

\begin{tabular}{|c|c|c|c|c|c|c|c|c|c|c|c|c|c|c|c|c|}
\hline Year & 2004 & 2005 & 2006 & 2007 & 2008 & 2009 & 2010 & 2011 & 2012 & 2013 & 2014 & 2015 & 2016 & 2017 & 2018 & 2019 \\
\hline Index & 4.35 & 4.37 & 4.39 & 4.4 & 4.42 & 4.45 & 4.47 & 4.49 & 4.52 & 4.54 & 4.57 & 4.6 & 4.64 & 5.34 & 5.38 & 5.42 \\
\hline
\end{tabular}

TABLE 3: Correlation coefficients and significance test results.

\begin{tabular}{lccccc}
\hline Industries & 1 & 2 & 3 & 4 & 5 \\
\hline Correlation coefficient & -0.894 & 0.589 & 0.874 & 0.547 & 0.691 \\
$p$ value & 0.001 & 0.021 & 0.001 & 0.035 & 0.004 \\
Test result & Pass & Pass & Pass & Pass & Pass \\
\hline
\end{tabular}

In addition, the IPP positively affects the T\&U of wholesale and retail (passing the significance test at the level of 0.05). To enhance the competitiveness of the industry, the operation and protection of intellectual properties are necessary for the following aspects of wholesale and retail: commodity trademarks, shop trademarks, product packaging design, shop decoration design, and licensing.

The promoting effect of the IPP on finance mainly manifests as pledge financing and securitization of intellectual properties (passing the significance test at the level of 0.05). As a financial innovation, the IPP plays a role in building a multilevel financial market.

The data suggest that the IPP is negatively correlated with the $\mathrm{T} \& \mathrm{U}$ of manufacturing (correlation coefficient $=-0.8939$ ), while the IPP is positively correlated with the total industrial output (correlation coefficient $=0.8027$ ). It does not mean that the T\&U of manufacturing overlooks the IPP. Instead, more efforts should be paid to the IPP during the $T \& U$ of manufacturing.

However, industrial T\&U is influenced by many factors. Pearson's correlation coefficients confirm that the IPP promotes the T\&U of some industries. But the result does not mean that the IPP outshines the other factors in the promotion of industrial T\&U. Finally, Pearson's correlation coefficients mainly reflect the macro relationship between the IPP and the T\&U of traditional industries. The specific role of the intellectual properties in the T\&U of each industry should be further studied on the microlevel.

\section{Conclusions}

This paper measures the T\&U levels of five representative industries in Zhejiang through shift-share analysis and examines their correlations with IPP intensity. The following conclusions were drawn:

(1) Manufacturing is not an advantageous industry in Zhejiang. Manufacturing lacks structural advantage and location advantage, as both advantages were falling in the report period.

(2) Wholesale and retail, lodging and catering, finance, and real estate are advantageous industries in Zhejiang. These industries are advantageous in either structure or location competitiveness.

(3) The IPP positively affects the T\&U of wholesale and retail, lodging and catering, finance, and real estate, as well as the total output of manufacturing.

\section{Data Availability}

The data used to support the findings of this study are available from the corresponding author upon request.

\section{Conflicts of Interest}

The authors declare that they have no conflicts of interest regarding the publication of this study.

\section{Acknowledgments}

This work was supported by Soft Science Program 2018, Department of Science and Technology, Zhejiang Province, China (Grant no. 2019C35047).

\section{References}

[1] G. Q. Xue and X. Y. Xiang, "Analysis of the development status and trends of traditional industries," Journal of Shaoxing University of Arts and Science, vol. 33, no. 7, pp. 47-51, 2013.

[2] T. Liu and Y. Ping, "Study progress of industry life cycle theory," Hunan Agricultural Sciences, vol. 2009, no. 8, pp. 93-96, 2009.

[3] J. F. Moore, "Predators and prey: a new ecology of competition," Harvard Business Review, vol. 71, no. 3, pp. 75-86, 1993.

[4] J. F. Mooer, The Death of Competition: Leadership and Strategy in the Age of Business Ecosystem, Harper Business, New York, NY, USA, 1996.

[5] B. L. Wang and H. Li, "On connotation and development path of regional industrial upgrading," Journal of Liaoning University (Philosophy \& Social Sciences), vol. 2015, no. 43, p. 80, 2015.

[6] X. Y. Tang, "Industrial upgrading: transfer, deepen or others-a technical view of path-selection," Research and Development, vol. 2010, no. 1, pp. 42-48, 2010.

[7] Q. Zhang, R. Mu, Z. Zhang et al., "Competitiveness evaluation of high-quality manufacturing development in the yangtze river economic belt," International Journal of Sustainable Development and Planning, vol. 15, no. 6, pp. 875-883, 2020.

[8] Y. Q. Xiong and D. Zeng, "Discussion on the decision-making method of the transformation of regional traditional industries," Statistics \& Decisions, vol. 2011, no. 11, pp. 44-47, 2011.

[9] C. Liu, "Multi-agent modeling of the collaborative operation of the producer service supply chain under the intelligent manufacturing clusters in the Yangtze river delta," Journal Européen des Systèmes Automatisés, vol. 53, no. 4, pp. 487-492, 2020.

[10] Y. Liu, "Transformation and upgrading of traditional industries in the new era: motivation, path and policy," Study \& Exploration, vol. 280, no. 11, pp. 108-115, 2018.

[11] S. J. Cheng and L. H. Tian, "Dynamic mechanism of high-tech industrialization in conventional industry," Journal of Changchun University, vol. 17, no. 9m, pp. 21-23, 2017.

[12] Y. X. Hong, "Direction and impetus in industrial structure transformation and upgrading," Seeking Truth, vol. 41, no. 1, pp. 57-62, 2014. 
[13] Y. Gao, "Measurement and driving factors of green total factor manufacturing energy efficiency in China," International Journal of Sustainable Development and Planning, vol. 15, no. 7, pp. 1017-1023, 2020.

[14] J. J. Ye, J. Wang, and Y. Zhang, "Analysis on transformation and upgrading levels of three industries in 11 prefectures of Zhejiang based on shift-share method," Discrete Dynamics in Nature and Society, vol. 2021, Article ID 2428602, 2021.

[15] Y. Gao, "The analysis of measuring upgrading of industrial structure and the constraint factors," Statistical Research, vol. 23 , no. 4, pp. 47-49, 2006.

[16] N. Li and W. P. Huang, "The impact of intellectual property protection on international trade- - a research summary," Modern Management Science, vol. 2018, no. 1, pp. 6-8, 2018.

[17] H. Y. Xiong and W. Yang, "A review of researches on the influence of intellectual property right protection on economic growth," Journal of Chongqing Technology and Business University (West Forum), vol. 17, no. 2, pp. 22-25, 2007.

[18] L. J. Chen, Intellectual Property Protection, Technological Innovation and Trade Structure Optimization, Zhejiang University, Hangzhou, China, 2012.

[19] S. P. Yan and L. Y. Zhang, "Review of the intellectual property protection of the creative industries," Science Technology and Law, vol. 3, no. 2, pp. 1-5, 2011.

[20] J. N. Li and Y. X. Shang, "A summary of issues concerning the protection of agricultural intellectual property rights," Economic Research Guide, vol. 2010, no. 14, pp. 141-142, 2010.

[21] Y. R. Zhang, Research on Safety Evaluation of Traditional Chinese Medicine Industry Based on Intellectual Property Protection, Nanjing University of Chinese Medicine, Nanjing, China, 2015.

[22] X. J. Li, "A summary of researches on the intellectual property protection of digital information resources," Modern Intelligence, vol. 25, no. 1, pp. 70-73, 2005.

[23] H. H. Qiu and Z. G. Qian, "A study on the intellectual property protection under the perspective of culture: a literature review," Journal of Guangxi Administrative Cadre Institute of Politics and Law, vol. 28, no. 5, pp. 65-69, 2013.

[24] Y. Zhou, Research on Customs Protection of Intellectual Property from the Perspective of Interest Balance, Shanghai Jiaotong University, Shanghai, China, 2013.

[25] W. X. Ye and L. C. Liu, "Measurement of Xi'an'Industrial transformation level and structure effects analysis," Mathematics in Practice and Theory, vol. 48, no. 8, pp. 72-81, 2017.

[26] Y. Gao, "The analysis of measuring upgrading of industrial structure and the constraint factors," Statistical Research, vol. 2006, no. 4, pp. 47-49, 2006.

[27] E. S. Dunn, "A statistical and analytical technique for regional analysis," Papers in Regional Science, vol. 6, no. 1, pp. 97-112, 1960.

[28] C. K. Daniel, Shift of Manufacturing Industries, Industrial Location and National Resources, Washington, DC, USA, 1942.

[29] D. Creamer, "Shifts of manufacturing industries," in Industrial Location and National Resources, pp. 85-104, Government Printing Office, Washington, DC, USA, 1943.

[30] R. X. Wang, Research on Industrial Transformation and Upgrading of Hebei Province under the Coordinated Development of Beijing-Tianjin-Hebei, Hebei University, Baoding, China, 2017.

[31] J. J. Wang, Research on Examination Questions of National College Students' Mathematical Contest in Modeling, National Defense Industry Press, Arlington, Virginia, 2019.

[32] J. J. Ye and Y. Z. Zhang, "Quantitative analysis of intellectual property protection intensity in Zhejiang province," Journal of
Zhejiang Industry \& Trade Polytechnic, vol. 19, no. 4, pp. 43-46, 2020.

[33] J. J. Ye, Y. L. Wang, and J. J. Wang, "Factor Analysis of the level of transformation and upgrading of the tertiary industry based on the double logarithm linear regression model," Special Economic Zone, vol. 2021, no. 9, pp. 131-136, 2021. 